\title{
INCORPORATION OF ESSENTIAL OILS FROM Piper aduncum INTO FILMS MADE FROM ARROWROOT STARCH: EFFECTS ON THEIR PHYSICOCHEMICAL PROPERTIES AND ANTIFUNGAL ACTIVITY
}

\author{
Anna Carolina Fernandes Valadares ${ }^{\mathrm{a}}$, Cassia Cristina Fernandes ${ }^{\mathrm{a}}$, Josemar Gonçalves de Oliveira Filho ${ }^{\mathrm{a}}$, Isabella Pelosi \\ Borges de Deus ${ }^{a}$, Thayanara Mayara de Lima ${ }^{a}$, Elizabeth Aparecida Josefi da Silva ${ }^{\text {a }}$ Edson Luiz Souchie ${ }^{\mathrm{a}}$ and Mayker \\ Lazaro Dantas Miranda ${ }^{\mathrm{b}, *, \mathbb{1}}$ \\ Instituto Federal de Educação, Ciência e Tecnologia Goiano, Campus Rio Verde, 75901-970 Rio Verde - GO, Brasil \\ 'Instituto Federal de Educação, Ciência e Tecnologia do Triângulo Mineiro, Campus Uberlândia Centro, 38411-104 Uberlândia \\ - MG, Brasil
}

Recebido em 17/01/2020; aceito em 05/03/2020; publicado na web em 20/04/2020

\begin{abstract}
Starch is a promising source of biopolymers and the incorporation of essential oils (EOs) into it can improve some biological properties of films. This study aimed at developing and characterizing barrier, biodegradability and optical properties of biopolymeric films made from arrowroot starch and at incorporating EOs from Piper aduncum leaves and inflorescences in order to analyze their antifungal activity against Rhizopus microsporus and Colletotrichum gloeosporioides. The casting method was used for developing arrowroot starch films and incorporating EOs into them. Resulting films exhibited satisfactory barrier properties, low water vapor permeability (WVP), transparency and good barrier property against UV-vis light, besides being $100 \%$ biodegradable. In addition, films enriched with EOs at $0.75 \%$ and $1.0 \%$ revealed promising antifungal activity. Results showed, for the first time, that arrowroot starch enriched with EOs from $P$. aduncum can potentially be used as an active film due to its excellent physicochemical properties and antimicrobial activity.
\end{abstract}

Keywords: bio-based films; Maranta arundinacea; food chemistry; phytopathogens.

\section{INTRODUCTION}

In the food industry, packaging plays a fundamental role in the maintenance of quality and integrity of food products up to consumption, since it prevents damages from happening throughout transportation and storage, besides providing aesthetic resources and information about these packaged products. ${ }^{1,2}$ The use of traditional packaging, which is usually made from petroleum derivates, has been increasing lately, mainly due to its strengths, such as low density and high mechanical and barrier properties. ${ }^{3}$ However, since this type of non-degradable material generates a lot of residues, technologies that use renewable sources to obtain natural biodegradable polymers have become a necessity worldwide. ${ }^{3}$ Besides, researchers who have evaluated the incorporation of EOs from plants into a certain natural polymer have mentioned that this procedure is an excellent strategy to preserve food quality, minimize growth of undesirable microorganisms on its surface and provide extra protection against oxidizing agents. ${ }^{3}$

Starch is a very promising biopolymer in the development of biodegradable films due to its high availability and low cost. ${ }^{4,5}$ Films made from starch are biodegradable, non-toxic, shiny and transparent. ${ }^{6}$ Arrowroot (Maranta arundinacea) is native to Latin America and has rhizomes which provide high starch content. In Brazil, the three cultivars of commercial importance are the crioula, the banana and the common ones. ${ }^{7}$ Since arrowroot has high starch content in its rhizomes, extraction of arrowroot starch is economically interesting because it has some advantages, such as excellent digestibility, gelatinization capacity at relatively low temperatures and special physicochemical characteristics, such as high amylose content, which is needed to develop films with good properties. $^{8,9}$

*e-mail: maykermiranda@iftm.edu.br
Besides exhibiting biodegradability, mechanical and barrier properties, biopolymers may work as active packaging by transporting antimicrobial agents, antioxidants and nutritional compounds, such as vitamins. ${ }^{10,11}$ Therefore, EOs have shown potential applicability to films and biopolymer coatings because they exhibit high antioxidant antimicrobial properties; most of them are generally recognized as safe (GRAS). ${ }^{12}$

Fungi that belong to the genus Rhizopus sp. are classified as Fungi (kingdom), Zygomicota (division), Zygomicetes (class), Mucolares (order) and Mucolaceae (family). The following species belong to the genus Rhizopus: Rhizopus oligosporus, Rhizopus arrhizus, Rhizopus circicans, Rhizopus delemar, Rhizopus oryzae, Rhizopus microsporus, Rhizopus formosa and Rhizopus stolonifer. Rhizopus species are especially important as plant and animal pathogens and bioindustrial fermenters for food and metabolite production. $^{13}$

Fungi that belong to the genus Colletotrichum are important phytopathogens in tropical and subtropical regions worldwide. They cause several diseases, such as anthracnosis, peduncle rot, and varicella in mango, avocado and papaya. The disease caused by Colletotrichum gloeosporioides is characterized by colorful stains on leaves, stems, fruits and flowers which usually increase and make infected plant tissues fade and die. This pathogen requires hot and humid conditions to infect different plant hosts, such as gymnosperm, angiosperm, ornamental and fruit ones, besides plantations and gramineous plants. ${ }^{14}$

Since our research group keeps focusing on EOs from Piper aduncum $^{15}$ and considering that there are no studies of biopolymeric films made from arrowroot starch enriched with essential oils, it should be highlighted that this paper is the first report of the incorporation of EOs into films made from this type of starch. It has been known that Piper aduncum is an important Piperaceae, since several studies found in the literature have shown its potential as a great producer of EOs with therapeutic properties. ${ }^{16}$ Therefore, this 
study aimed at developing biodegradable films made arrowroot starch into which EOs from Piper aduncum leaves and inflorescences were incorporated, at determining some of their physicochemical properties and at investigating their antifungal activity against Rhizopus microsporus and Colletotrichum gloeosporioides.

\section{MATERIAL AND METHODS}

\section{Plant material and extraction of EOs}

Procedures used for acquiring the plant material and extracting EOs from $P$. aduncum leaves and inflorescences are the ones that have previously been described by our research group..$^{15}$ In this case, EOs were refrigerated at $4 \pm 2{ }^{\circ} \mathrm{C}$ and stored up to the moment in which they were incorporated into the filmogenic solutions.

\section{Development of biodegradable films}

Biodegradable films were obtained by the casting method, in agreement with the methodology proposed by Issa and his collaborators, ${ }^{17}$ with some modifications. In order to obtain films, $5 \mathrm{~g}$ commercial arrowroot starch was dissolved in $100 \mathrm{~mL}$ distilled water; the mixture was moderately agitated at room temperature $\left(25^{\circ} \mathrm{C}\right)$. Afterwards, this solution was heated at $80^{\circ} \mathrm{C}$ under constant agitation for 30 minutes. After starch gelatinization, glycerol was added as a plasticizer $(30 \% \mathrm{w} / \mathrm{w})$; this dispersion was then agitated for 5 minutes. When the filmogenic solution reached $40{ }^{\circ} \mathrm{C}$, a previously prepared suspension of EOs from Piper aduncum in Tween 80 (SigmaAldrich $\left.{ }^{\circledR}\right)(0.25 \mathrm{~g} / \mathrm{g}$ EOs) was incorporated into it under constant agitation for 15 minutes.

Filmogenic solutions made from arrowroot starch - into which EOs from $P$. aduncum leaves and inflorescences were incorporated - were poured on polyethylene trays and dried in an oven with air circulation at $35^{\circ} \mathrm{C}$ for about 48 hours, up to the point in which films detached from the trays. Final concentrations of EOs from P. aduncum leaves and inflorescences were $0.25 \%, 0.50 \%, 0.75 \%$ and $1 \%(\mathrm{v} / \mathrm{v})$, besides a control treatment (with no EOs).

\section{Thickness and moisture}

Film thickness was measured by a digital micrometer, with $0.01 \mathrm{~mm}$ accuracy. Ten spots were measured on every film and thickness mean was calculated. Humidity content was determined by loss of film mass after films had been dried in an oven at $110^{\circ} \mathrm{C}$, up to the moment they reached constant weight. Three replicates were carried out in every treatment. ${ }^{18}$

\section{Measurement of water solubility}

In order to determine water solubility of resulting active films, samples that measured about $2 \mathrm{~cm}^{2}$ were dried in an oven at $105^{\circ} \mathrm{C}$ for 3 hours and then weighed so that initial mass (Mi) could be determined. Afterwards, they were immersed in $50 \mathrm{~mL}$ distilled water and kept under constant agitation at $25^{\circ} \mathrm{C}$ for 24 hours. Then, samples were filtered through Whatman filter paper Grade 1 . In the literature, ${ }^{10}$ films were dried at $105{ }^{\circ} \mathrm{C}$ for 24 hours and weighed (Mf). Every treatment was analyzed in triplicate. Film solubility (\%) was calculated by the following equation (1):

$$
\text { Water solubility }(\%)=\frac{(\mathrm{Mi}-\mathrm{Mf})}{\mathrm{Mi}} \times 100
$$

\section{Water vapor permeability}

Water vapor transmission rate (WVTR) and water vapor permeability (WVP) were evaluated in agreement with Salas-Valero et al. by the water method. ${ }^{19}$

In order to carry it out, $10 \mathrm{~mL}-$ Becker flasks were filled with $5.0 \mathrm{~g}$ deionized water, sealed with the films and then placed in a desiccator which held a saturated solution of potassium nitrate $\left(\mathrm{KNO}_{3}-\right.$ SigmaAldrich $($ ). Masses in the Becker flasks were measured every hour for 8 hours and then again at the $24^{\text {th }}$ hour. ${ }^{20}$ The experiment was performed in triplicate. Both WVTR and WVP were calculated by the following equations ( 2 and 3 ):

$$
\mathrm{WVTR}=\frac{\mathrm{m}}{\mathrm{t} \times \mathrm{A}}
$$

where $\mathrm{m}$ is mass loss, $\mathrm{t}$ is time and $\mathrm{A}$ is film area. WVP was calculated by multiplying WVTR by film thickness (E) and dividing it by the pressure difference $(\Delta \mathrm{P})$

$$
\mathrm{WVP}=\frac{\mathrm{WVTR}}{(\Delta \mathrm{P})} \times \mathrm{E}
$$

\section{Biodegradability}

Biodegradability was analyzed by the methodology proposed by Martucci and Ruseckaite, ${ }^{21}$ with some modifications. Film samples $(2 \times 3 \mathrm{~cm})$ were dried up to constant weight so that initial mass (Mi) could be found. Samples were placed in microperforated polyethylene bags, enabling microorganisms and humidity to access them. However, packaging was conducted so that samples could be recovered later.

Samples were then buried in previously prepared organic soil in a plastic box at relative humidity around $40 \%$ and at room temperature $\left(25^{\circ} \mathrm{C}\right)$.

Fifteen days after the experiment outline, bags with biodegraded samples were removed from the soil, washed with distilled water and dried up to constant weight (Mf). Biodegradability (\%) was calculated by the following equation (4):

$$
\text { Biodegradability }(\%)=\frac{(\mathrm{Mf}-\mathrm{Mi})}{\mathrm{Mi}} \times 100
$$

\section{Color analysis}

The analysis of film color was carried out by a colorimeter (HunterLab, Color Quest II, Reston, USA). Parameters under evaluation were $\mathrm{L}^{*}$ (luminosity) and chromaticity ( $\mathrm{a}^{*}$ and $\mathrm{b}^{*}$ ). Measurements were conducted by placing the white pattern on the film sample $\left(\mathrm{L}^{*}=99.94, \mathrm{a}^{*}=-0.52\right.$ and $\left.\mathrm{b}^{*}=1.43\right) . \Delta \mathrm{E}$ was related by the mean of five measurements per film. ${ }^{12}$ Difference in color $(\Delta \mathrm{E})$ was calculated by the following equation (5):

$$
\Delta \mathrm{E}:\left[(\Delta \mathrm{L})^{2}+(\Delta \mathrm{a})^{2}+(\Delta \mathrm{b})^{2}\right]^{1 / 2}
$$

\section{Analysis of the UV-vis light transmission rate}

Ultraviolet-visible light transmission of films was carried out by a UV-vis spectrophotometer (LAMBDA 750, PerkinElmer). Film samples were placed on a film holder and transmittance was measured at wavelengths that ranged from 250 to $850 \mathrm{~nm}$, in agreement with the methodology employed by Hosseini et al..$^{22}$

\section{Scanning electron microscopy (SEM)}

The analysis of film microstructure was carried out by a scanning electron microscope (JSM - IT300, Jeol) in the Microscopy Laboratory 
at the Centro Regional para o Desenvolvimento Tecnológico e Inovação de Goiás (CRTI - GO). Images were magnified 1000x.

\section{Antifungal activity}

Antifungal activity of films was analyzed against phytopathogenic fungi Colletotrichum gloeosporioides (CCT 5177) and Rhizopus microsporus var. oligosporus (IOC 3801) by a disk diffusion test. ${ }^{20}$ Petri dishes, half full with PDA, were inoculated with $100 \mu \mathrm{L}$ suspension with $10^{5} \mathrm{CFU} \mathrm{mL} \mathrm{m}^{-1}$. Then, three samples of films which had been cut in circles with about $5 \mathrm{~mm}$ in diameter were placed on every dish. Dishes were incubated at $25 \pm 2{ }^{\circ} \mathrm{C}$ for 5 days. Finally, diameters of the zone of inhibition were measured.

\section{Statistical analysis}

Experiments had a completely randomized design (CRD), data were submitted to the analysis of variance (ANOVA) and means of replicates were analyzed by the Tukey's test at $5 \%$ probability by the ASSISTAT software.

\section{RESULTS AND DISCUSSION}

Films made from arrowroot starch were transparent and bright. According to Gordillo et al., ${ }^{6}$ arrowroot (Maranta arundinacea L.) has high starch content (>99\%) and its amylose content is above $40 \%$. Both contents are responsible for forming strong polymeric matrices for film production. These characteristics make arrowroot starch become an excellent option to develop biodegradable films and, as described by the literature, glycerol acted as an appropriate plasticizer. $^{2}$

It should be highlighted that when EOs from $P$. aduncum leaves and inflorescences are added to films, they get less transparent. The higher the concentration of EOs, the whiter the filmogenic solutions and, consequently, the more turbid the films. To face this impasse and to meet the need for homogeneous filmogenic solutions, the emulsifier Tween 80 had to be incorporated into formulations of arrowroot starch films. Its volume varied, depending on concentrations of EOs, in order to ensure better homogenization, as suggested by Souza et al..$^{23}$

\section{Physical and barrier properties}

Figure 1 shows that resulting film thickness, in millimeters, did not differ significantly $(\mathrm{p}>0.05)$, since values ranged from $0.108 \mathrm{~mm}$ to $0.122 \mathrm{~mm}$ after EOs from $P$. aduncum were incorporated into the films. Therefore, agglomeration of EO particles on films was found to exert little effect on thickness variation. Regarding film thickness, similar findings were observed by Song, Zuo, and Chen, ${ }^{24}$ who reported minimum changes when they incorporated different concentrations of EOs from lemon into films.

Humidity contents of films were found to decrease when concentrations of EOs increased (Figure 2). This behavior was expected since EOs have hydrophobic features which lead to decrease in polysaccharides/water interaction and result in low humidity contents. These results agree with data described by Song, Zuo, and Chen, ${ }^{24}$ who studied films made from corn and wheat starch into which EOs from lemon had been incorporated. There was also similarity between data found by the study described by this paper and the ones found by Shen and Kamdem ${ }^{3}$ who perceived decrease in humidity of films made from chitosan as EOs from citronella and cedarwood were incorporated into it.

Solubility was evaluated because it is an important parameter in the characterization of biopolymeric films, mainly because when they are applied to food packaging, they should exhibit low solubility, i.e., high resistance to water. ${ }^{25,26}$ Figure 3 shows that incorporation of EOs from $P$. aduncum leaves and inflorescences into them led to decrease in their solubility, by comparison with the control (films with no EOs), which exhibited $38.04 \%$ solubility while films into which EOs from leaves and inflorescences were incorporated $(1.0 \%$ of every oil) had $33.99 \%$ and $32.92 \%$, respectively. Results showed decrease in the hydrophilic nature of films, a fact that is explained by the interaction between components of EOs and hydroxyl groups of films, which cannot interact with water molecules and, consequently, generate films that are more resistant to water. ${ }^{24,27}$ Jahed et al. ${ }^{10}$ also observed decrease in solubility in water of chitosan films when EOs from Carum copticum were incorporated into them. In a similar study, Ghasemlou et al. ${ }^{28}$ found decrease in solubility in water of corn starch films into which two types of EOs from Zataria multiflora and Mentha pulegium were incorporated. According to Kavoosi, Dadfar, and Purfar, ${ }^{29}$ effects of the incorporation of additives into the polymeric matrix on solubility depend on the type of additive, its concentration and its indexes of hydrophilicity and hydrophobicity. Therefore, these hydrophilic compounds are expected to increase film solubility, whereas hydrophobic ones, such as chemical constituents found in EOs, are supposed to contribute to solubility decrease.

Results of the analysis of WVP followed the alignment found in analyses of humidity content and solubility in water. There was significant decrease $(\mathrm{p}<0.05)$ in film permeability as the result

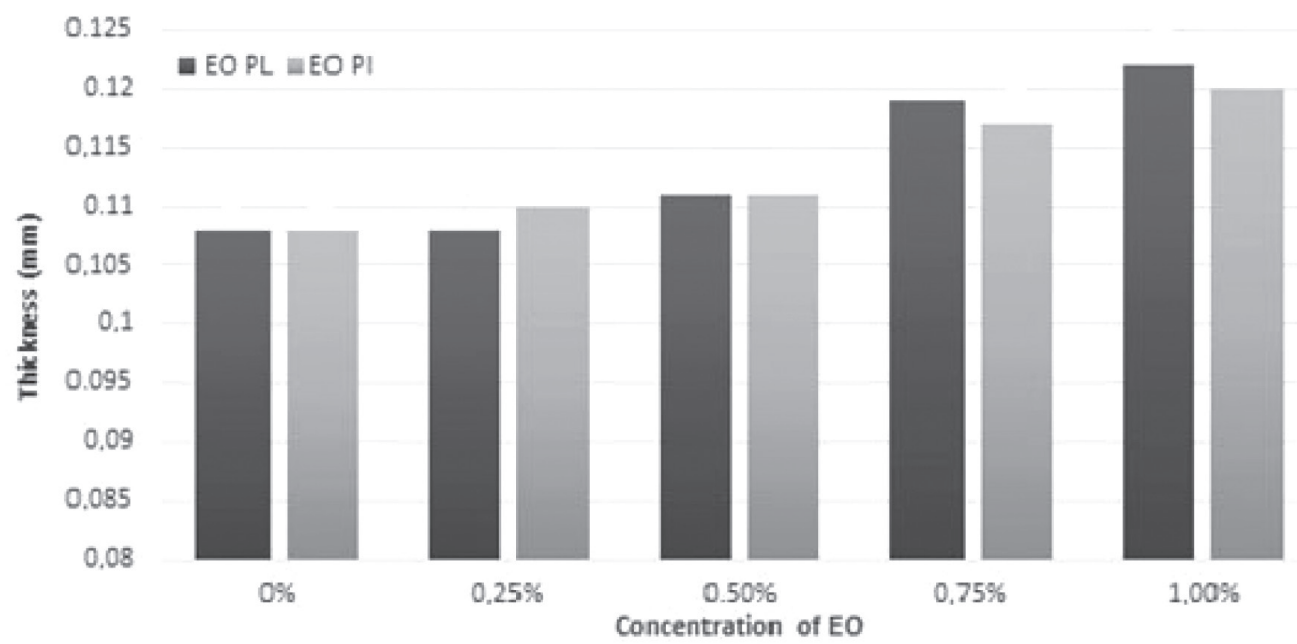

Figure 1. Thickness ( $\mathrm{mm}$ ) of films made from arrowroot starch enriched with EOs from P. aduncum leaves (EO PL) and inflorescences (EO PI) 


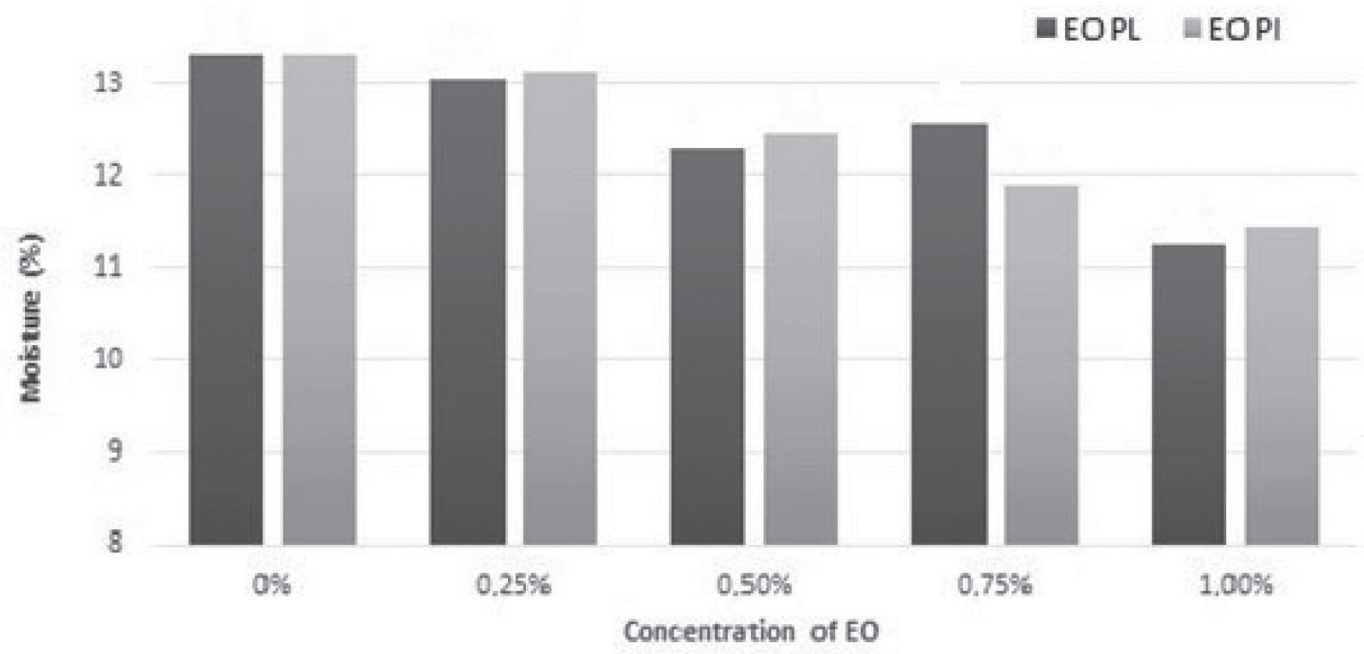

Figure 2. Moisture (\%) of films made from arrowroot starch enriched with EOs from P. aduncum leaves (EO PL) and inflorescences (EO PI)

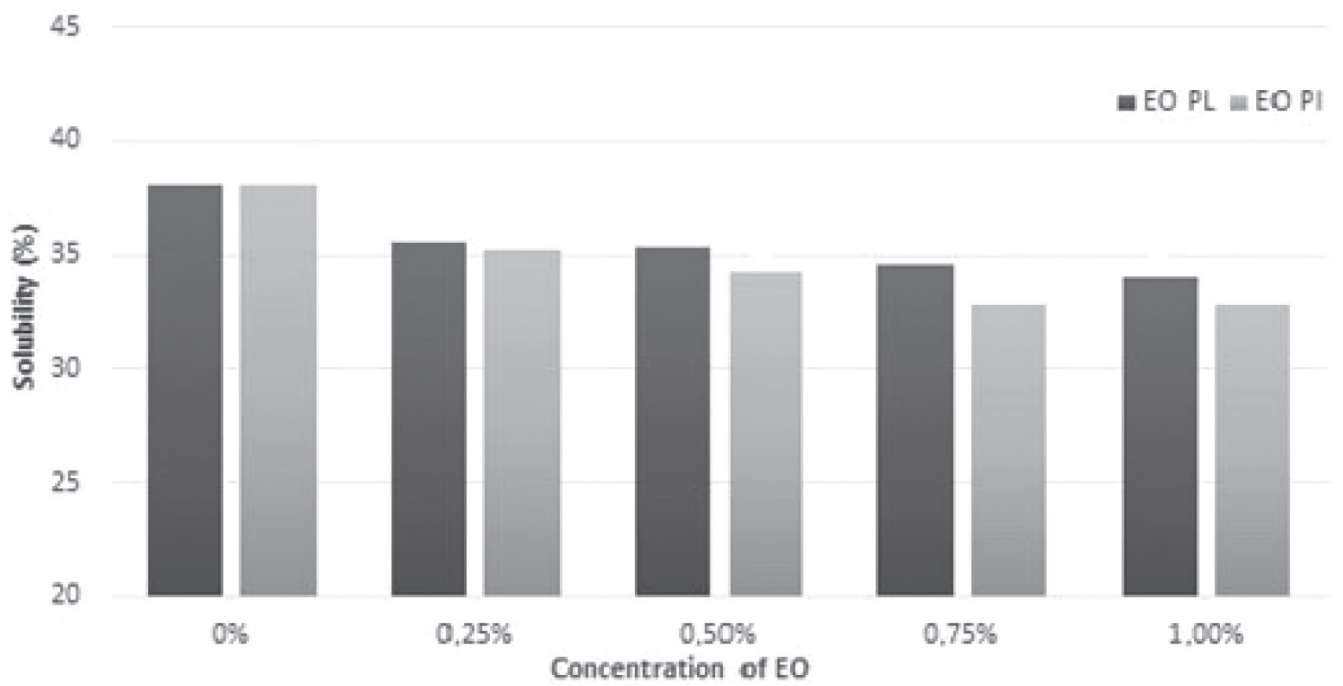

Figure 3. Solubility (\%) of films made from arrowroot starch enriched with EOs from P. aduncum leaves (EO PL) and inflorescences (EO PI)

of increase in concentrations of EOs from $P$. aduncum leaves and inflorescences (Figure 4). It should be highlighted that there was more decrease in permeability when EOs from leaves were incorporated into the films, by comparison with EOs from inflorescences. This result may be associated with the fact that two parts of a plant may yield EOs with different chemical composition, inferring that the

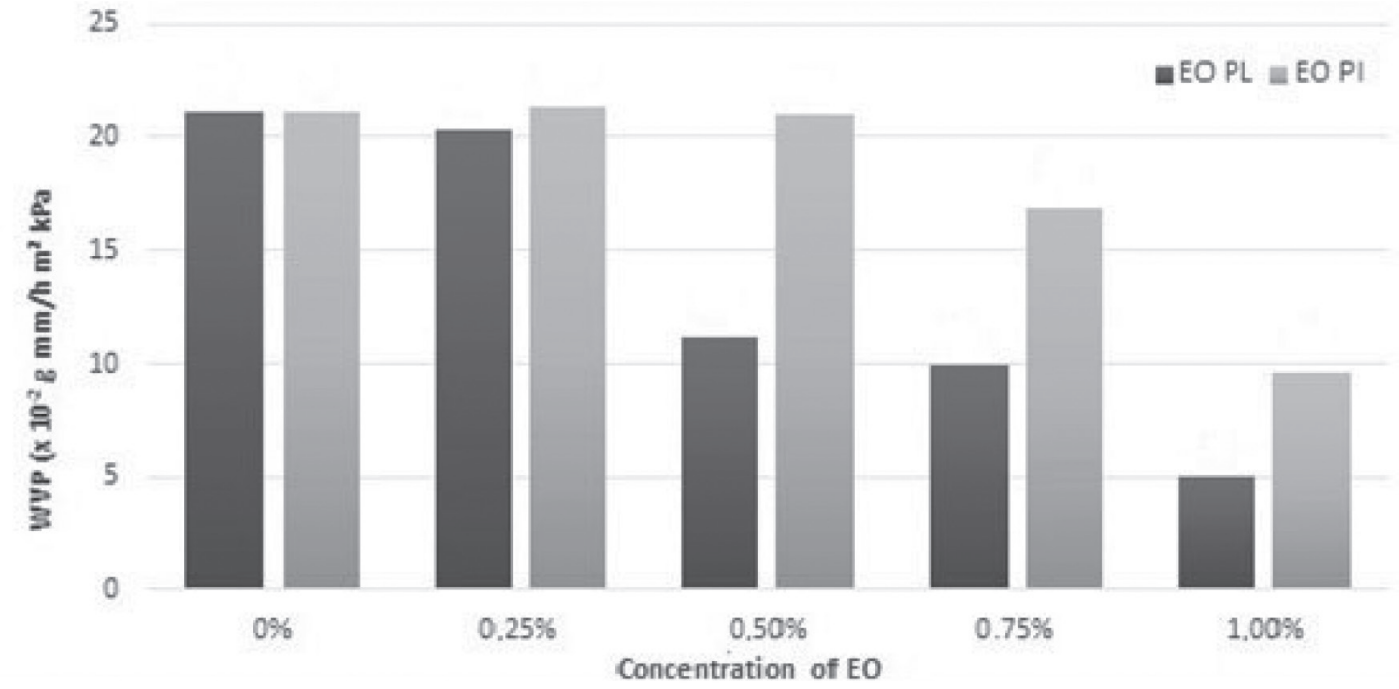

Figure 4. Water vapor permeability (WVP) $\left(x 10^{-2} \mathrm{~g} \mathrm{~mm} / \mathrm{h} \mathrm{m} \mathrm{m}^{2} \mathrm{kPa}\right)$ of films made from arrowroot starch enriched with EOs from P. aduncum leaves (EO PL) and inflorescences (EO PI) 
polarity of compounds found in different parts of a plant may be related to decrease in film permeability. This difference was shown by a previous study which focused on describing the chemical composition of EOs from $P$. aduncum. ${ }^{15} \mathrm{WVP}$ of films has been described as a constant value of water vapor permeation at a certain temperature. This parameter is directly related to the chemical composition, since it depends on the chemical structure and the morphology of the material under analysis. ${ }^{5}$ It is known that one of the main functions of food packaging is to avoid - or, at least, mitigate - transference of humidity from food to the environment; thus, WVP should be as low as possible. ${ }^{30}$ Results of WVP of films made from arrowroot starch with EOs from $P$. aduncum leaves and inflorescences were similar to the ones found by Salarbashi et al. ${ }^{18}$ in their study of chitosan films with EOs from Zataria multiflora and Mentha pulegium, in which increase in concentrations of EOs that were incorporated into films triggered decrease in WVP.

\section{Biodegradability}

The analysis of biodegradation of arrowroot films with EOs from $P$. aduncum leaves and inflorescences was carried out in the soil; its relative humidity was kept at $40 \%$ so that films could be submitted to conditions found in the natural environment. The mixed microflora found in organic soil (bacteria, actinobacteria, fungi and protozoa) may act during film degradation. ${ }^{21}$ Fifteen days after the implementation of the experiment, total degradation of arrowroot films $(100 \%)$ was observed when samples of organic soil were collected. Stoll et al..$^{31}$ reported $96.27 \%$ of degradation of films made from manioc starch into which anthocyanins had been incorporated; since it took place just 10 days after the beginning of the experiment, it showed the relevant degradation capacity of films made from starch.

\section{Optical properties}

It is important to evaluate the color of biopolymeric films for food packaging since it may influence consumers' acceptance. ${ }^{24}$

Incorporation of EOs from $P$. aduncum leaves into arrowroot films led to a little increase in $\mathrm{L}^{*}$ values, by comparison with the control. This increase was significant when EO PL concentration reached $0.50 \%$, thus showing that films became clearer. When EO PI was incorporated into films, there was little decrease in $\mathrm{L}^{*}$ values; it was only significant when EO PI concentration was $0.75 \%$. L* values of all films got close to 100 (white), a fact that showed that arrowroot films enriched with EOs from $P$. aduncum are glossy. ${ }^{32}$ Besides, incorporation of EOs increased negative $a^{*}$ values significantly. Negative $a^{*}$ values of chromatic coordinates show that films tended to "greener" hues, mainly after having incorporated EO PL. The highest $\mathrm{a}^{*}$ values were found in the films enriched with EO PL at 1.0\% (-1.48). Regarding $b^{*}$ values, no films, except the one enriched with EO PI $(1.0 \%)$, exhibited significant differences $(\mathrm{p}<0.05)$, by comparison with the ones of the control. Chromatic coordinates $b *$ with positive values show that films exhibited yellow hues in this parameter. Even though $\Delta \mathrm{E}$ values varied considerably after EO PL was incorporated into the films, the ones into which EO PI was incorporated exhibited values that were closer to the ones of the control (Table 1).

Concerning parameters of color, Hafsa et $a l .^{33}$ observed that they were directly affected in chitosan films after EOs from Eucalyptus globulus were incorporated into them. These authors used concentrations of $0,1,2,3$ and $4 \%$; increase in concentrations led to decrease in film luminosity and changes in color towards red $\left(a^{*}\right)$ and yellow $\left(b^{*}\right)$.

Figure 5 shows light transmission rates (\%) of arrowroot films into which EOs from $P$. aduncum leaves and inflorescences were incorporated, in the range from 250 to $850 \mathrm{~nm}$. Results found in the UV region (from 250 to $370 \mathrm{~nm}$ ) showed that the control films made from arrowroot starch (with no EOs) exhibited good barrier property against UV light, since it decreased up to $85 \%$ of UV transmission in this range. Adding EOs from $P$. aduncum leaves and inflorescences to films decreased light transmission in the UV range up to $100 \%$ at all concentrations under analysis. Guerrero et $a l .{ }^{34}$ evaluated light transmission of films made from soybean protein into which epoxidized soybean oil, olive oil and lactic acid were incorporated, by comparison with some common plastic films (oriented polypropylene and low-density polyethylene). Light transmission rates of both oriented polypropylene and low-density polyethylene films were $71.78940 \%$ and $27.64510 \%$, respectively, at $280 \mathrm{~nm}$. Films made from soybean protein and films into which oils and lactic acid were incorporated had their light transmission rates significantly decreased $(0.00871 \%$ in the case of films made only from soybean protein at $280 \mathrm{~nm}$ ). Light transmission rate of arrowroot films enriched with EOs from $P$. aduncum was as low as the one of films produced by Guerrero et al. ${ }^{34}$ It shows the potential of films made from biopolymeric material, such as starch and soybean protein, as barriers against lipid oxidation in food caused by exposure to UV light.

Decrease in the light transmission rate when EOs from $P$. aduncum were added to films was also found in the visible light region, mainly at $1.0 \%$ of EO PI (Figure 5). These results show the capacity EOs have to decrease light transmission rate in the UV-vis region; it may be explained by light dispersion in the interface of oil droplets on the film matrix..$^{22,35}$ Therefore, packaging of food with high content of fat should ideally exhibit low light transmission rate

Table 1. Parameters CIELAB of color $L^{*}$ (luminosity), $a^{*}$ and $b^{*}$ (chromaticity) and the total color difference $(\Delta \mathrm{e})$ of films made from arrowroot starch enriched with EOs from $P$. aduncum leaves (EO PL) and inflorescences (EO PI)

\begin{tabular}{|c|c|c|c|c|}
\hline Treatment & $L^{*}$ & $a^{*}$ & $b^{*}$ & $\Delta e$ \\
\hline Control & $87.91 \pm 0.48^{\mathrm{cd}}$ & $-1.126 \pm 0.005^{\mathrm{h}}$ & $3.244 \pm 0.16^{\mathrm{b}}$ & $12.179 \pm 0.47^{\mathrm{bc}}$ \\
\hline EO PL $0.25 \%$ & $88.24 \pm 0.01^{\mathrm{bc}}$ & $-1.264 \pm 0.005^{\mathrm{d}}$ & $3.37 \pm 0^{\mathrm{b}}$ & $11.885 \pm 0.01^{\mathrm{cd}}$ \\
\hline EO PL $0.50 \%$ & $88.43 \pm 0.008^{b}$ & $-1.394 \pm 0.01^{\mathrm{c}}$ & $3.492 \pm 0.01^{\mathrm{b}}$ & $11.727 \pm 0.006^{\mathrm{d}}$ \\
\hline EO PL $0.75 \%$ & $88.43 \pm 0.02^{\mathrm{b}}$ & $-1.432 \pm 0.004^{\mathrm{b}}$ & $3.504 \pm 0.01^{\mathrm{b}}$ & $11.727 \pm 0.01^{\mathrm{d}}$ \\
\hline EO PL $1.0 \%$ & $88.92 \pm 0.007^{\mathrm{a}}$ & $-1.484 \pm 0.005^{\mathrm{a}}$ & $3.272 \pm 0.44^{\mathrm{b}}$ & $11.223 \pm 0.06^{\mathrm{e}}$ \\
\hline EO PI $0.25 \%$ & $87.89 \pm 0.007^{\mathrm{d}}$ & $-1.15 \pm 0.01^{\mathrm{g}}$ & $3.408 \pm 0.008^{\mathrm{b}}$ & $12.227 \pm 0.005^{\mathrm{b}}$ \\
\hline EO PI $0.50 \%$ & $87.65 \pm 0.008^{\mathrm{de}}$ & $-1.18 \pm 0.007^{\mathrm{f}}$ & $3.442 \pm 0.01^{\mathrm{b}}$ & $12.465 \pm 0.009^{\mathrm{ab}}$ \\
\hline EO PI $0.75 \%$ & $87.51 \pm 0.01^{\mathrm{e}}$ & $-1.198 \pm 0.008^{\mathrm{e}}$ & $3.512 \pm 0.05^{\mathrm{b}}$ & $12.619 \pm 0.01^{\mathrm{a}}$ \\
\hline EO PI $1.0 \%$ & $87.59 \pm 0.004^{\mathrm{de}}$ & $-1.15 \pm 0.007^{\mathrm{g}}$ & $3.904 \pm 0.01^{\mathrm{a}}$ & $12.609 \pm 0.007^{\mathrm{a}}$ \\
\hline
\end{tabular}



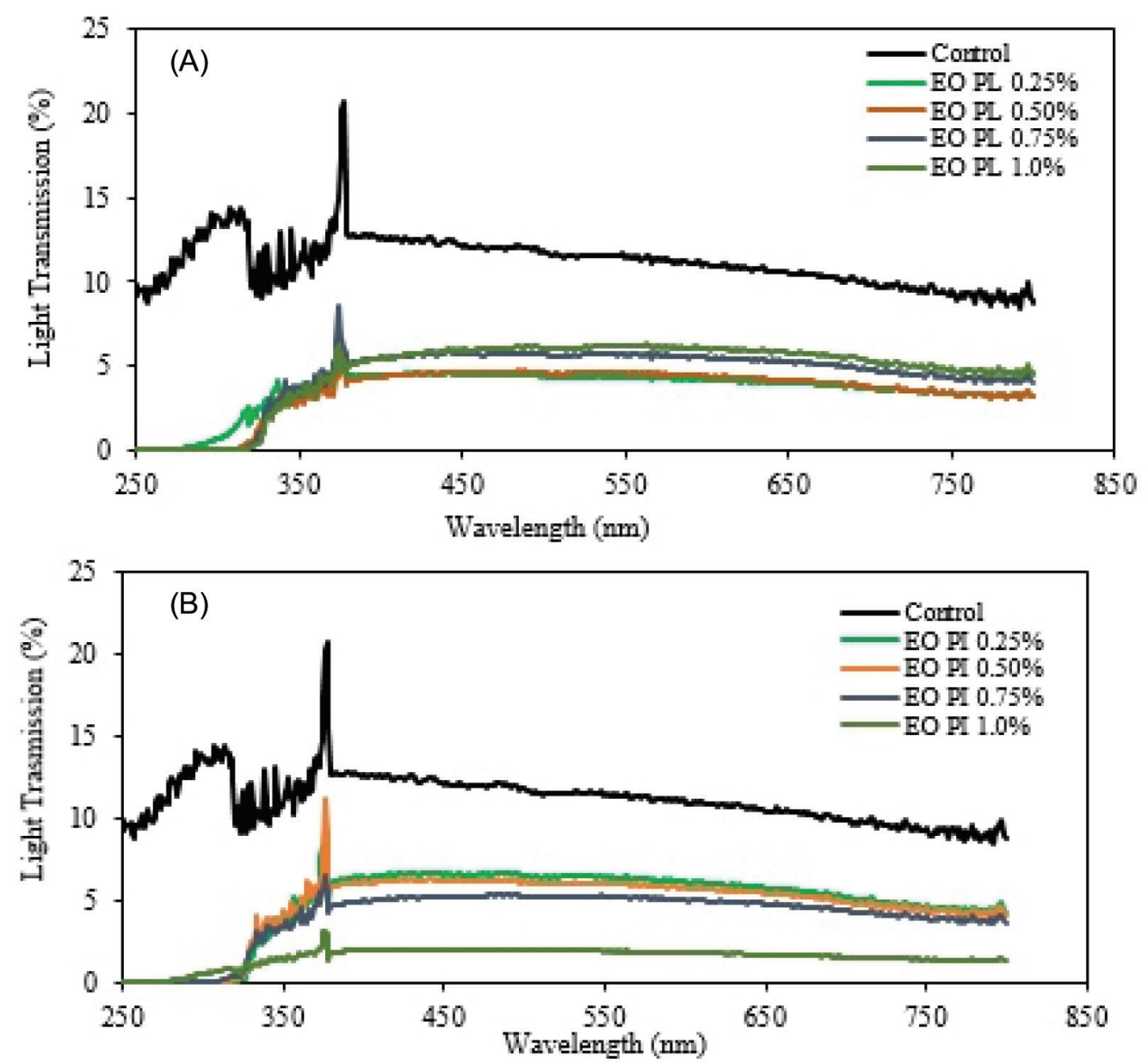

Figure 5. UV-vis light transmission rate of films made from arrowroot enriched with EOs from P. aduncum leaves (A) and inflorescences (B)

so as to avoid the process of lipid oxidation, if possible, since it leads to deterioration of this type of food..$^{31}$

\section{Antifungal activity}

Incorporation of antimicrobial agents, such as EOs, into biopolymeric matrices aims at avoiding deterioration caused by microbial contamination on food surfaces, thus, decreasing the need for antimicrobials which are usually incorporated into most food. ${ }^{36}$ Films into which antimicrobial agents were incorporated tend to release these compounds in the medium they were placed on (PDA, in this case), resulting in a clean inhibition zone around film cuts. ${ }^{37,38}$

Control films (with no EOs) did not show any growth inhibition of fungi under investigation (Rhizopus microsporus and Colletotrichum gloeosporioides). Fungi grew on films. When EOs were incorporated into films at $0.75 \%$ and $1.0 \%$ (EO PI) and at $1.0 \%$ (EO PL), these films were active in the control of $R$. microsporus growth, i.e., there was no fungus growth on them. It was not found when EOs were at lower concentrations $(0.25 \%$ and $0.50 \%)$, in which the fungus grew on the whole dish, even on films. On dishes inoculated with the fungus C. gloeosporioides, films into which oils were incorporated at $0.50 \%$, $0.75 \%$ and $1.0 \%$ (EO PL) and $0.75 \%$ and $1.0 \%$ (EO PI) showed potential to inhibit fungus growth on films. However, neither control films nor the ones enriched with EOs at $0.25 \%$ exhibited antifungal potential, since the fungus grew on them (Figure 6).

Antifungal activity of films made from manioc starch enriched with EOs from cinnamon and clove against both fungi P. Commune and E. amstelodami was also evaluated by Souza et al. ${ }^{23}$ Their results showed that control films (with no EO) did not exhibit any antifungal activity against any fungi under investigation, as expected. On the other hand, when EOs (from cinnamon and clove) were incorporated into films and when their concentrations were increased, inhibition areas of films increased.

Antimicrobial activity of films enriched with EOs is dosedependent on their concentrations. For instance, low concentrations may not show inhibition of microbial growth. Besides, they may affect the diffusion capacity of EOs from the film matrix to the medium (PDA), thus, influencing formation of inhibition halos directly. ${ }^{39}$ The fact that films made from arrowroot enriched with EOs from $P$. aduncum leaves and inflorescences do not exhibit inhibition halos after the incubation period may be related to low concentrations of EOs, which hinders formation of visible halos. However, high concentrations under analysis were found to maintain no fungus growth on films; it shows that concentrations above $1.0 \%$ of EOs incorporated into the polymeric matrix made from arrowroot starch may not show formation of inhibition halos.

\section{Scanning electron microscopy (SEM)}

Images show starch granules that were not gelatinized during heating, mainly on control films and on the ones enriched with $0.25 \%$ of EO PI. Control films enriched with EO PL at concentrations of $0.25 \%$ and $0.50 \%$ and the ones enriched with EO PI at $0.25 \%$ had similar characteristics, with a homogeneous microstructure. However, films enriched with EO PL at $0.75 \%$ and $1.0 \%$ exhibited microstructures with some cracks. Besides, films enriched with EO PI at $0.50 \%, 0.75 \%$ and $1.0 \%$ were found to exhibit deeper cracks in their microstructures (Figures 7 and 8). 


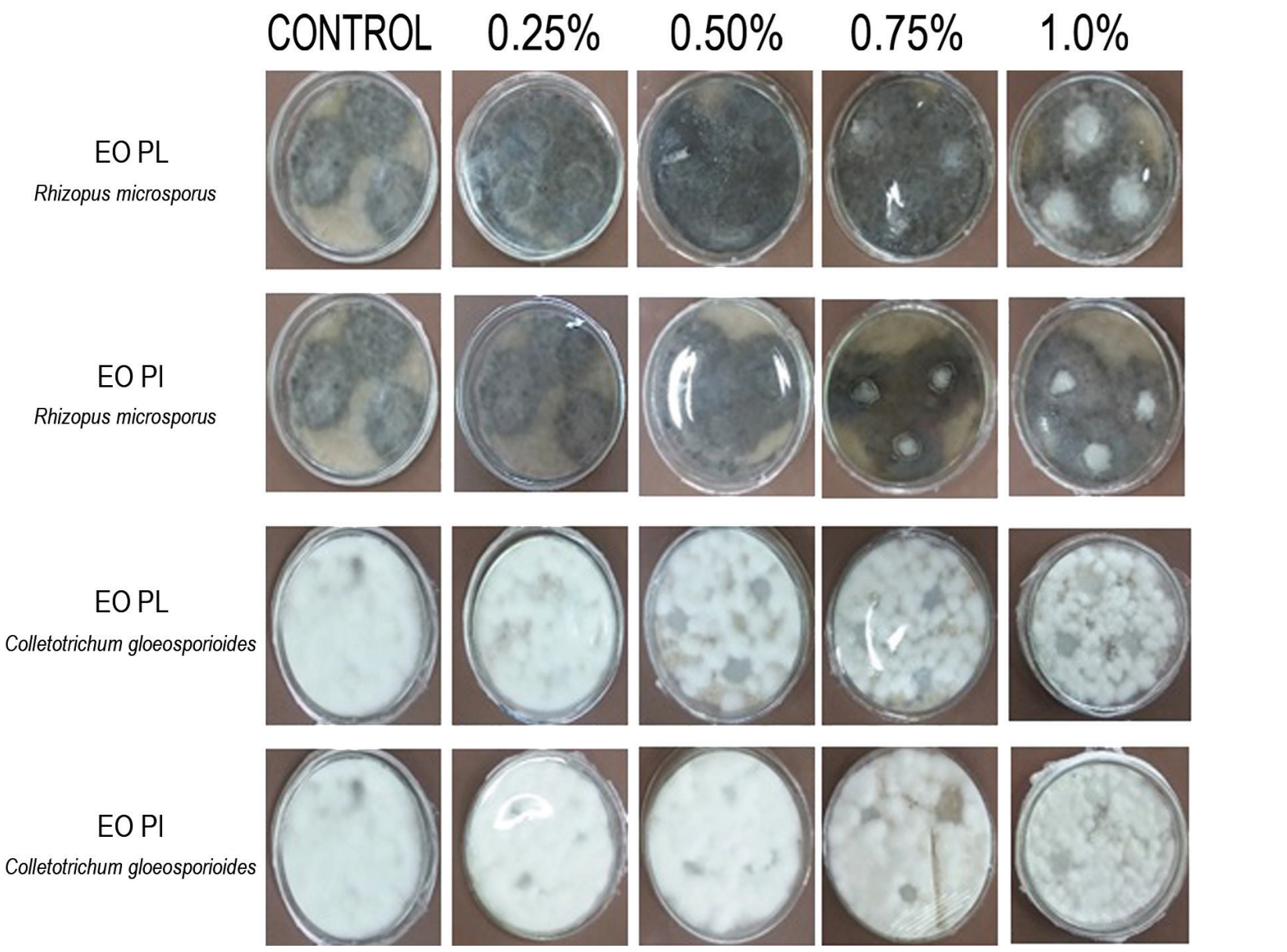

Figure 6. Antifungal activity of films made from arrowroot starch enriched with EOs from P. aduncum leaves (EO PL) and inflorescences (EO PI) against both fungi Rhizopus microsporus and Colletotrichum gloeosporioides
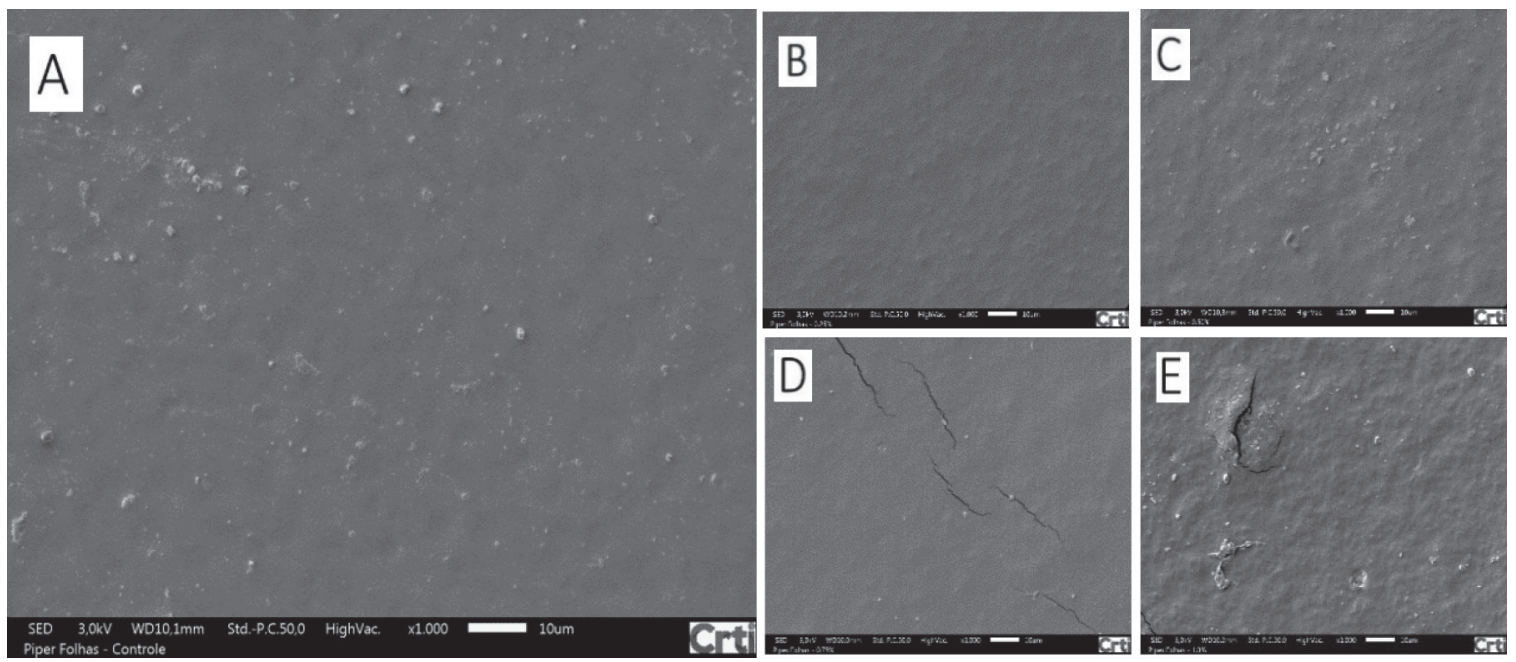

Figure 7. SEM images (magnified 1000x) of films made from arrowroot starch: control (A) and enriched with EO PL at 0.25\% (B), 0.50\% (C), 0.75\% (D) and $1.0 \%(E)$

Incorporation of some additives into the filmogenic solution may change the mechanism of film formation. Increase in the distance among polysaccharide units of films may be related to phase segregation, since starch is a hydrophilic polymer and essential oils are hydrophobic active agents. In addition, essential oils disturb the process of solvent (water) evaporation and change patterns of film formation. ${ }^{40}$

Changes in the microstructure of films caused by the incorporation of EOs into them were found by Ghasemlou et al. ${ }^{28}$ in films made from chitosan enriched with EOs from Zataria multiflora Boiss and Mentha pulegium. It was similar to what happened to films evaluated by Pires and Moura ${ }^{41}$ who observed nanoemulsions of oils incorporated into alginate matrices as rugosity and agglomerates in images carried out by SEM.

It should be highlighted that a study conducted by Hafsa $e t ~ a l .{ }^{33}$ showed that incorporation of EOs from Eucalyptus globulus into chitosan films, mainly at the highest concentrations under 

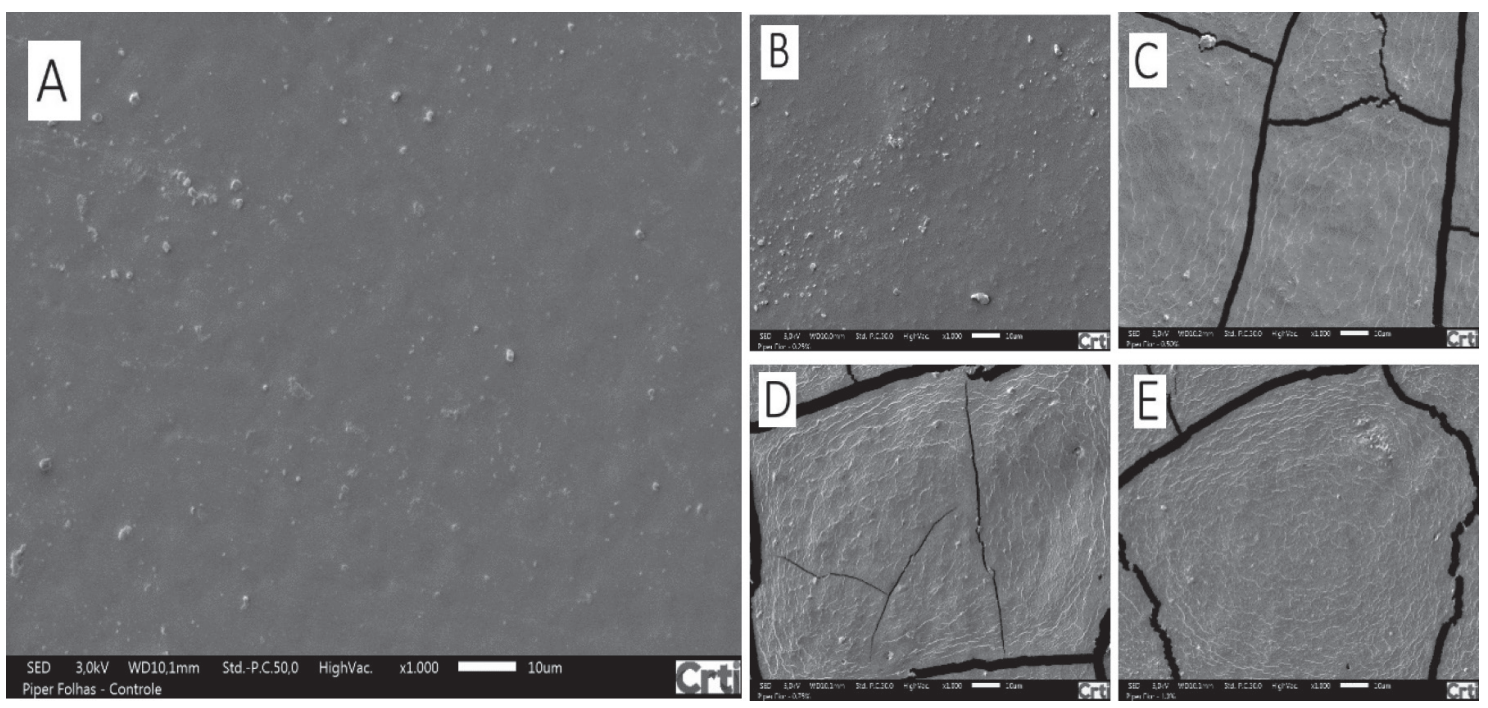

Figure 8. SEM images (magnified 1000x) of films made from arrowroot starch: control (A) and enriched with EO PI at 0.25\% (B), 0.50\% (C), 0.75\% (D) and $1.0 \%(E)$

investigation ( $3 \%$ and $4 \%$ ), led to considerable changes in film microstructures, since they ended up exhibiting heterogeneous surface on which oil droplets were arrested by the continuous polysaccharide path. Concentrations of EOs which were investigated by the study reported in this paper $(0.25 \%, 0.50 \%, 0.75 \%$ and $1.0 \%)$ were lower than those used by Hafsa et al. ${ }^{33}(1 \%, 2 \%, 3 \%$ and $4 \%)$; oil droplets were not found on film structures by SEM.

\section{CONCLUSIONS}

Results found by this study showed the potential that arrowroot (Maranta arundinacea) starch has as raw material to develop biopolymeric and biodegradable films which exhibit promising antifungal activity when EOs from $P$. aduncum leaves and inflorescences are incorporated into them. Physicochemical properties of films under study were satisfactory and revealed the possibility of applying them to food as biopolymeric films. In addition, their biodegradability and high antifungal activity against both fungi Rhizopus microsporus and Colletotrichum gloeosporioides should be highlighted. In short, films made from arrowroot starch and enriched with EOs from $P$. aduncum can be considered a sustainable alternative to be used for active food packaging.

\section{ACKNOWLEDGMENTS}

The authors are grateful to FAPEG, CNPq, CAPES and IF Goiano - Campus Rio Verde for their financial support.

\section{REFERENCES}

1. Kechichian, V.; Ditchfield, C.; Veiga-Santos, P.; Tadini, C. C.; LWT -Food Sci. Technol. 2010, 43, 1088.

2. Haq, M. A.; Jafri, F. A.; Hasnain, A.; J. Food Sci. Technol. 2016, 53, 2606.

3. Shen, Z.; Kamdem, D. P.; Int. J. Biol. Macromol. 2015, 74, 289.

4. Davoodi, M.; Kavoosi, G.; Shakeri, R.; Int. J. Biol. Macromol. 2017, $104,173$.

5. Perazzo, K. K. N. C. L.; Conceição, A. C. V.; Santos, J. C. P.; Assis, D. J.; Souza, C. O.; Druzian, J. I.; PLoS One 2014, 9, e105199.

6. Gordillo, C. A. S.; Valencia, G. A.; Zapata, R. A. V.; Henao, A. C. A.; Int. J. Food Eng. 2014, 10, 727.

7. Leonel, M.; Cereda, M. P.; Food Sci. Technol. 2002, 22, 65.
8. Nogueira, G. F.; Fakhouri, F. M.; Oliveira, R. A.; Carbohydr. Polym. 2018, 186, 64.

9. Charles, A. L.; Cato, K.; Huang, T. C.; Chang, Y. H.; Ciou, J. Y.; Chang, J. S.; Lin, H. H.; Food Hydrocolloids 2016, 53, 187.

10. Jahed, E.; Khaledabad, M. A.; Almasi, H.; Hasanzadeh, R.; Carbohydr. Polym. 2017, 164, 325

11. Flores-López, M. L.; Cerqueira, M. A.; Rodríguez, D. J.; Vicente, A. A.; Food Eng. Rev. 2015, 8, 292.

12. Noshirvani, N.; Ghanbarzadeh, B.; Gardrat, C.; Rezaei, M. R.; Hashemi, M.; Coz, C. L.; Coma, V.; Food Hydrocolloids 2017, 70, 36.

13. Gryganskyi, A. P.; Golan, J.; Dolatabadi, S.; Mondo, S.; Robb, S.; Idnurm, A.; Muszewska, A.; Steczkiewicz, K.; Masonjones, S.; Liao, H. L.; Gajdeczka, M. T.; Anike, F.; Vuek, A.; Anishchenko, I. M.; Voigt, K.; Hoog, G. S.; Smith, M. E.; Heitman, J.; Vilgalys, R.; Stajich, J. E.; G3 2018, 8, 2007.

14. Gautam, A. K.; J. Plant Physiol. Pathol. 2014, 2, 1.

15. Valadares, A. C. F.; Alves, C. C. F.; Alves, J. M.; Deus, I. P. B.; Filho, J. G. O.; Santos, T. C. L.; Dias, H. J.; Crotti, A. E. M.; Miranda, M. L. D.; An. Acad. Bras. Ciênc. 2018, 90, 2691

16. Monzote, L.; Scull, R.; Cos, P.; Setzer, W. N.; Medicines 2017, 4, 49.

17. Issa, A.; Ibrahim, S. A.; Tahergorabi, R.; Foods 2017, 6, 43.

18. Salarbashi, D.; Tajik, S.; Ghasemlou, M.; Shojaee-Aliabadi, S.; Noghabi, M. S.; Khaksar, R.; Carbohydr. Polym. 2013, 98, 1127.

19. Salas-Valero, L. M.; Tapia-Blácido, D. R.; Menegalli, F. C.; Quim. Nova 2015, 38, 14 .

20. Ma, Q.; Zhang, Y.; Critzer, F.; Davidson, P. M.; Zivanovic, S.; Zhong, Q.; Food Hydrocolloids 2016, 52, 533.

21. Martucci, J. F.; Ruseckaite, R. A.; J. Appl. Polym. Sci. 2009, 112, 2166.

22. Hosseini, S. F.; Rezaei, M.; Zandi, M.; Farahmandghavi, F.; Ind. Crops Prod. 2015, 67, 403.

23. Souza, A. C.; Goto, G. E. O.; Mainardi, J. A.; Coelho, A. C. V.; Tadini, C. C.; LWT -- Food Sci. Technol. 2013, 54, 346.

24. Song, X.; Zuo, G.; Chen, F.; Int. J. Biol. Macromol. 2018, 107, 1302.

25. Khazaei, N.; Esmaiili, M.; Djomeh, Z. E.; Ghasemlou, M.; Jouki, M.; Carbohydr. Polym. 2014, 102, 199.

26. López-Mata, M. A.; Ruiz-Cruz, S.; Silva-Beltrán, N. P.; Ornelas-Paz, J. J.; Ocaño-Higuera, V. M.; Rodríguez-Félix, F.; Cira-Chávez, L. A.; Del-Toro-Sánchez, C. L.; Shirai, K.; Int. J. Polym. Sci. 2015, ID974506.

27. Jouki, M.; Mortazavi, S. A.; Yazdi, F. T.; Koocheki, A.; Carbohydr. Polym. 2014, 99, 537.

28. Ghasemlou, M.; Aliheidari, N.; Fahmi, R.; Shojaee-Aliabadi, S.; Keshavarz, B.; Cran, M. J.; Khaksar, R.; Carbohydr. Polym. 2013, 98, 1117. 
29. Kavoosi, G.; Dadfar, S. M. M.; Purfard, A. M.; J. Food Sci. 2013, 78, E244.

30. Hosseini, S. F.; Rezaei, M.; Zandi, M.; Ghavi, F. F.; Food Chem. 2013, $136,1490$.

31. Stoll, L.; Silva, A. M.; Lahnke, A. O. S.; Costa, T. M. H.; Flores, S. H.; Rios, A. O.; J. Food Process. Preserv. 2017, e13218.

32. Souza, V. G. L.; Fernando, A. L.; Pires, J. R. A.; Rodrigues, P. F.; Lopes, A. A. S.; Fernandes, F. M. B.; Ind. Crops Prod. 2017, 107, 565.

33. Hafsa, J.; Smach, M. A.; Khedher, M. R. B.; Charfeddine, B.; Limem, K.; Majdoub, H.; Rouatbi, S.; LWT -- Food Sci. Technol. 2016, 68, 356.

34. Guerrero, P.; Hanani, Z. A. N.; Kerry, J. P.; La Caba, K.; J. Food Eng. 2011, 107, 41 .
35. Tongnuanchan, P.; Benjakul, S.; Prodpran, T.; Food Chem. 2012, 134, 1571.

36. Van Long, N. N.; Joly, C.; Dantigny, P.; Int. J. Food Microbiol. 2016, $220,73$.

37. Ojagh, S. M.; Rezaei, M.; Razavi, S. H.; Hosseini, S. M. H.; Food Chem. 2010, 122, 161.

38. López, P.; Sánchez, C.; Batlle, R.; Nerín, C.; J. Agric. Food Chem. 2007, 55,8814 .

39. Wang, L.; Liu, F.; Jiang, Y.; Chai, Z.; Li, P.; Cheng, Y.; Jing, H.; Leng, X.; J. Agric. Food Chem. 2011, 59, 12411.

40. Peng, Y.; Yin, L.; Li, Y.; Int. J. Food Sci. Technol. 2013, 48, 44.

41. Pires, V. G. A.; Moura, M. R.; Quim. Nova 2017, 40, 1. 